organically affected, or, if "functionally," shows such a degree of lack of tone in the cardiac muscle that the recruit should only be accepted on probation. I can scarcely expect the writer of the memorandum to agree with me on this point, for I think I do him no injustice when I state that, judging from his public utterances on the subject on various occasions, he would not hesitate to accept one who showed organic valvular lesion provided the muscular action of the heart satisfied him. I presume, however, that experience has satisfied the Army Medical Service that, notwitlistanding exceptions to the rule (usually accidentaliy discovered), there is wisdom in absolutely rejecting the recruit with organic valvular disease of the heart.

The "cardio-pulmonary bruit" the writer of the annotation on the recruit's heart in the same number of the Journal appears to regard as synonymous with the "functional nurmur." It is, however, exocardial and negligible, except in so far as it may occasionally denote some enlargement of the organ by the pulmonary rub against the heart, cliefly towards the end of inspiration.

The negligible functional bruit at the apex of the heart should disappear on assuming the erect position and on exercise. Basic systolic bruits may persist and be less important under the same circumstances.

As regaids the frequency of these functional bruits in adolescents, the younger the man the more likely is such a murmur to be met with, but even in youth they cannot be said to be common, as is often asserted. Among a hundred healthy boys at a publie school how many manifest them? Very few ; and what is true of schoolboys of the so-called better classes is also true of the poorer, as practice among them teaches. Their very transiency, moreover, denotes a temporary abnormality; their persis tence renders them not negligible for prognostic purposes.

What is true of the heart affected with functional endo cardial murmurs is true also of the extra-systolic heart. The extra-systole, which is not abolished by the augmented and accelerated heart of exercise, is one not often met with in the young. When it persists, as it often does in the older, it is usually associated with other signs denoting cardiac fault.

"Auricular fibrillation" at the recruiting age will usually be found associated with mitral valvular disease of which the fibrillation is the more or less direct consequence, and a recruit presenting himself with it should be rejected on account of the mechanical defect.

The " heart-block" deternainable by the methods usually pursued by the examiner of recruits and at the recruiting age is so rare that its occurrence would almost be a medical curiosity, and the country will lose the services of few on this account.

The rhythmical variation of pulsation associated with respiration, so long known and common in the young, in whom it is often coupled with an occasional reduplication of the second sound, being purely plyysiological, is, of course, no cause for rejection. At all ages it may be induced by forced respiration and its detection by an examiner ought to be regarded as evidence of his care and accuracy in investigation.

Finally, the accelerated and augmented action of the emotional heart ought also to lead to few rejections. Even the inexperienced, who themselves possess hearts and have known emotion, are unlikely to err on this point.

I trust that these remarks will not be regarded as unduly critical on my part. For my experience of cardiac failure among soldier's during the present war has been considerable and has convinced me that the estimation of the recruit's heart is so important a point in judging of his fitness for active service that $I$. feel it a duty to raise a warning note against that minimization of mechanical error in cardiac action which in civil life may be merely unwise, but in military life, under the conditions of modern war, may prove disastrous, not only to the individual, but be a source of expense and invalidism inconvenient to the service.

ThE late Dr. Bruce Goff, of Botbwell, Renfrewshire, lef personal estate in the United Kingdom valued at $£ 94,218$.

THE Government of the Republic of Panama proposes to establish a universi $y$-in Colon. The United States Government has under consideration a proposal to found one at San José de Puerto Rico.

\section{THE EFFECT OF EXERTION ON THE CIRCLLATION."}

\author{
Bу J. M. MACPHAIL, M.D.EDix., \\ EDINBCRGH
}

CoNsiderable attention has recently been directed to the effect of exertion on the circulation, and many attempts have been made to gauge the efficiency of the diseased heart by its reaction to exertion. The stiudy of the subject has yielded conflicting results, but the weight of evidence points to a rise in systolic pulse pressure after moderate exertion, and a fall in blood pressure where the heart is failing or the exertion excessive.

Of the tests employed sphygmometric obscrvations have held a prominent place, but doubt has been thrown on their value as an index to the work performed by the heart or a guide to its functional ability, ${ }^{1}$ and a method is surcly defective which merely registers the maximal pressure but fails to indicate the pressure maintained between the arterial beats. Thus, with a high systolis pressure of sudden and fugitive nature we may have associated an extremely low diastolic pressure, a combination which probably represents greater cardiac ineffi. ciency than a blood pressure of lower but better sustained character. The pulse of aortic incompetence, with .its high systolic pulse pressure and sudden fall to a. very low diastolic pressure, is an example of this type of inefficiency.

In recording my results, I have used the spliygmograph of the Mackenzie clinical polygraph, with its long tracing paper, and the method adopted was as follows.

A tracing of the pulse was taken in the sitting and in the erect posture, and, with the sphygmograph and paper still in position, the patient was asked to ascend twenty steps. Immediately on arrival the clockwork was again set in motion, and the result was a study of the pulse within the first second or so of the completion of the exertion. The pulse changes in character so rapidly from moment to moment that time is all-important in recording the delicate changes.

The sphygmograph has lost caste recently, and is considered quite unreliable as a guide to blood pressure; but it affords a means of estimating the power of the heart, as compared with the resistance it has to overcome (Lauder Brunton ${ }^{2}$ ), and gives some idea of the condition of the cir. culation during a complete cardiac cycle. The tracings exhibit a fall in palse tension, as shown by a lowering of the aortic notch, a flattening of the diastolic portion of the tracing, and a falling away or absence of the predicrotic wave. There is also very frequently a great variation of systolic and diastolic pressure with each pulse wave, and a marked respiratory irregularity. Though I have no doubt the systolic pulse pressure is increased, the actual result is the production of a collapsing pulse with a great lowering of diastolic pressure. Schott, ${ }^{8}$ Mahomed, ${ }^{4}$ and Sansom, have called attention to this characteristic feature of the pulse after exertion. A reduction in arterial tension occurred in every instance; but this was more evident where the patients examined suffered from cardiac disease with failing compensation; and the more serious the cardiac disease, the more pronounced was this reduction in tension.

A glance at the tracings reveals the extreme changes induced by exertion, even to a close mimicry of the pulse found associated with such diseased conditions as aortic incompetence and the terminal stages of pneumonia.

In testing cardiac efficiency it has been claimed that the most reliable indications are the subjective symptoms of breathlessness and palpitation, but it is of interest to have a permanent record of the changes.

Subjoined are the tracings with their explanations.

\section{Case I.}

A male patient, aged 63, suffering from cardiac dilatation, with oedema' of the ankles, a mitral systolic murmur and with oedema of the ankles, a mitral systolic murmur and $140 \mathrm{~mm}$. in the sitting posture. Exertion causes a very evident and distinct fall of arterial tension, the artery being apparently as empty at the end of cardiac systole as at the end of diastole.

* Extract from thesis for M.D. ,. Edinburgh University, 1913. 
The predicrotic wave is all but lost; whilst respiratory irregularity and hyperdicrotism appear. Such a fall of tension in an

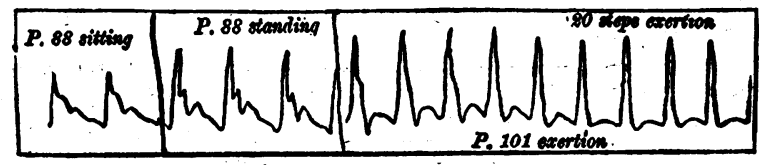

Fig. 1

old patient with moderately high arterial pressure indicate serious cardiac inadequacy.

Case Ir.

A woman, aged 63, suffering from beart failure, with oedems of the ankles, a mitral systolic murmur and a grossly irregular pulse. On exertion the irregularity becomes extreme, but the pressure varies with each arterial beat; the pulse is markedly

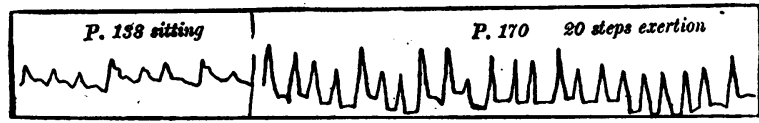

Fig. 2.

affected by respiration, and is apparently very empty during diastole. There is a complete absence of the predicrotic wave, and some of the pulsations are almost monocrotic.

In these two cases the almost complete disappearance of the predicrotic wave is presumptive evidence of a diminished systolic pulse pressure.

\section{CASE III.}

The man of 72 years whose pulse tracing this represents was not a patient, but was so breathless on exertion that some degree of cardiac inefficiency seemed certain. The tracing degree of cardiac ineffiency seemed certain. The tracing is a prominent symptom. The systolic pulse pressure was

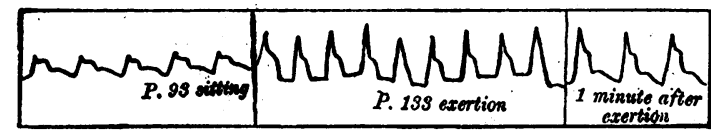

Fig. 3.

$150 \mathrm{~mm}$. in the sitting posture, but apart from some hypertrophy of the heart there were no other evident signs of cardiac disease. The respiratory irregularity, the sudden and abrupt nature of the systole, and the empty condition of the artery nature of the systole, and the empty condition of the artery to a higher tension one minute afterwards.

CASE IV.

A male patient of 56 years, suffering from cardiac dilatation, with a mitral systolic murmur, oedema of the ankles, engorge ment of the liver, and well-marked dyspnoea. On exertion feeble contractions, with a flat platean at the summit, such as

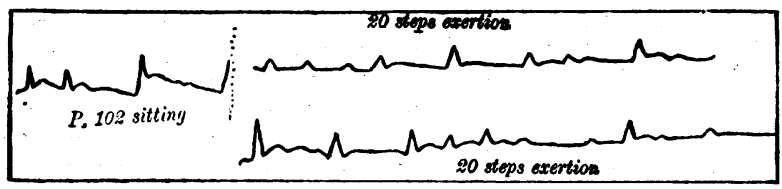

Fig. 4

we associate with heart failure, develop. There are also intervals during which the pulse fails to affect the tracing. The evidence here points to a much diminished systolic pulse pressure.

A female patient of 67 years, suffering from chronic bronchitis, with cardiac dilatation, and a mitral systolic murmur. While at rest, the pulse of this patient was irregular in rate and rhythm, with abont five "intermissions" during the minute, not shcwn in the tracing; but after exertion there

$$
\text { P. } 180 \text { sitting. }
$$

is great irregularity of the pulse. At first one " extra-systole" occurs after each full contraction, but towards the end of the tracing these increase in number till they finally leave the descending line, and appear as small, rounded, independent contraotions along the base line.

Case vi.

This continuous tracing shows the effect the running of half a mile at a quick pace had on the pulse of a healthy boy of 18 year's. Before the start the sphygmograph was applied to the wrist, but some adjustment was called for at the end of the first quarter.mile. The attention necessary at the end of the half-mile wis very slight, and after inserting the smoked paper an additional 100 yards were run to keep up the action. The result was chronicled almost immediately. The prominent features are the very

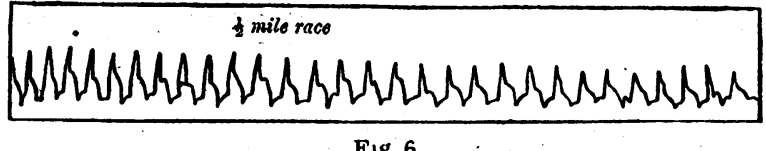

low diastolic pressure, the marked respiratory irregularity, the hyperdicrotism, and the variations in force and fullness of the artery with each pulse wave. The effect is not unlike that produced by the inlalation of amyl nitrite, and certainly suggests a pulse of low tension, though the systolic pulse pressure is undoubtedly powerful. After a few seconds the arterial tension begins to improve.

Cleghorn ${ }^{6}$ took pulse tracings of runners two minutes after a Marathon race, and he and Williams ${ }^{7}$ found that there was a great reduction in blood pressure after such severe exertion.

1. Exertion causes a rise in systolic pulse pressure, though a general vaso-dilatation may nullify this effect.

2. There is always a lowering of diastolic pressure.

3. In heart disease will failing compensation the fall in diastolic pressure is most pronounced; and there is often an almost complete absence of the predisrotic wave, pointing to a diminished systolic pulse pressure.

\section{REFERENCES}

1 Janeway: Clinical Study of Blood Pressure. 2 Lauder Brunton: Lancet, May, 1912 . ${ }^{3}$ Schott: New York Med. Journ.. April, 1902. of Diseases of the Heart, 1892, 6 Blake Larrabee : The Ciagnosis Boston Med. Journ. September, 1902, vol. cxli. 7 Williams, Boston Med. Journ., vol. cxil.

\section{RAPIDITY OF THE PULSE DEPENDENT UPON PeRsistent DISTURBANCE OF THE} VASOMOTOR MECHANISM.

\section{BY KNOWLES BONEY, M.D.LOND.,} CAPTAIN R.A:M.C.

The following remarks are based upon observation of a series of twenty cases of rapid pulse in my charge. The subjects were all Indians drawn from units of the Indian Expeditionary Force in Flanders, who, after undergoing treatment at a casualty clearing station and base hospital for various injuries and ailments, had eventually been transferred to a convalescent camp. In this camp it was noticed that a certain number of the men did not improve as they should; they always appeured languid, tired, and generally unfit. On being questioned no particular complaint would be made, the man probably saying that he felt weak and unable to do anything; his general aspect coincided with this view of things.

The brief physical examination possible under the circumstances revealed nothing much except the rapidity of the pulse, and the patient was placed among the group requiring prolonged convalescence. ' Improvement was either very slow or did not take place at all, and it soon became apparent that there was a permanent residue of "unfits" in the camp-a residue which was slowly but surely increasing.

I was privileged to investigate and report upon a certain number of these " unfits," and the following remarks are based upon observation of a series of twenty during a period of six weeks.

The experience gained by medical officers during the South African war on the subject of cordite and its effect on the heart is probably well known, and in order, as far as possible, to eliminate errors of this nature, the patients were placed in a special ward, and were not allowed to leave it for any purpose, a guard being mounted to enforce this.

Every article of clothing and kit was taken away from them except water bottles. Food and water were brought 